\title{
THE SYSTEM APPROACH AND PROBLEMS OF MODELING NATURAL-TECHNOGENIC SAFETY
}

\author{
Yakub E. Dadaev \\ Chechen State University, Grozny, Russian Federation \\ Samart D. Hazhmuradova \\ Chechen State University, Grozny, Russian Federation
}

\begin{abstract}
The paper substantiates the necessity of using the system analysis as an effective tool for studying security problems, in particular the problems of ensuring natural and man-made safety, in the study of natural and anthropogenic threats. The article shows the interrelation and interdependence of natural and man-made safety factors, which is confirmed at the fundamental level today. The article identifies the main types of naturalanthropogenic hazards, such as those of natural, man-made, social character. To study the problems of natural and man-made safety, the model of an ecological-technogenic system is proposed, which adequately reflects the main processes that determine the problems of natural and man-made safety; the specificity of the system approach to problems of natural and man-made safety is determined. This model allows us to classify the risks of the complex system operation. The article, using the methodology of system analysis, highlights the most important methodological principles to be followed when exploring ecological and man-made systems as well. They are: the principle of optimal simplicity, the principle of social responsibility, the principle of interdisciplinarity of the ecological-technogenic system, the principle of objectivity, the principle of hierarchy of goals, the principle of values and "economic realism", the principle of analysing of constantly developing systems, the principle of system synthesis. The author formulates the main stages of the system analysis of natural and technological safety problems. The author concludes that developing the fundamentals of risk-based analysis of emergency situation consequences requires a special attention.
\end{abstract}

Key words: natural-technogenic safety, system, system approach, technosphere, society, ecosystem.

Citation. Dadaev Ya.E., Hazhmuradova S.D. The System Approach and Problems of Modeling NaturalTechnogenic Safety. Vestnik Volgogradskogo gosudarstvennogo universiteta. Seriya 3, Ekonomika. Ekologiya [Science Journal of Volgograd State University. Global Economic System], 2019, vol. 21, no. 2, pp. 157-165. (in Russian). DOI: https://doi.org/10.15688/jvolsu3.2019.2.14

\section{СИСТЕМНЫЙ ПОДХОД И ПРОБЛЕМЫ МОДЕЛИРОВАНИЯ ПРИРОДНО-ТЕХНОГЕННОЙ БЕЗОПАСНОСТИ}

\author{
Якуб Элхазурович Дадаев \\ Чеченский государственный университет, г. Грозный, Российская Федерация \\ Самарт Динисламовна Хажмурадова \\ Чеченский государственный университет, г. Грозный, Российская Федерация
}

Аннотация. В статье обоснована необходимость использования системного анализа как эффективного инструмента исследования проблем безопасности, в частности, природно-техногенной, при изучении природно-антропогенных угроз. Показана взаимосвязь и взаимозависимость природных и техногенных факто- 
ров безопасности, которая подтверждается на фундаментальном уровне. Определены основные виды опасностей природно-антропогенного характера, такие как природные, техногенные, социальные. Предложена модель эколого-техногенной системы, которая адекватно отражает основные процессы, характеризующие проблемы природно-техногенной безопасности, выявлена специфика системного подхода в проблемах природно-техногенной безопасности. Данная модель позволяет классифицировать риски функционирования сложных систем. С использованием методологии системного анализа выделены важнейшие методологические принципы, которых необходимо придерживаться, исследуя эколого-техногенные системы: оптимальной простоты, социальной ответственности, междисциплинарности эколого-техногенной системы, объективности, иерархии целей, ценностей и «экономического реализма», анализа постоянно развивающихся систем, системного синтеза. Сформулированы основные этапы системного анализа проблем природно-техногенной безопасности. Сделан вывод о том, что отдельного внимания требует разработка основ риск-ориентированного анализа последствий ЧС.

Ключевые слова: природно-техногенная безопасность, система, системный подход, техносфера, социум, экосистема.

Цитирование. Дадаев Я. Э., Хажмурадова С. Д. Системный подход и проблемы моделирования природно-техногенной безопасности // Вестник Волгоградского государственного университета. Серия 3, Экономика. Экология. - 2019. - Т. 21, № 2. - С. 157-165. - DOI: https://doi.org/10.15688/jvolsu3.2019.2.14

\section{Введение}

Общепризнанной тенденцией цивилизационного развития на современном этапе является значительный рост социально-экономических потерь от различных опасностей, в основе которых природные и антропогенные процессы. В своем большинстве опасности имеют естественно-техногенный характер, и рост уязвимости общества к опасностям обусловлен социально-экономическими факторами. Постоянное присутствие природно-техногенных опасностей в процессах социального развития позволяет утверждать об их системности и необходимости учета при прогнозировании социального развития.

Взаимозависимость природных и техногенных факторов безопасности сегодня подтверждена на фундаментальном уровне. Так, геологи открыли новый феномен в динамике земной коры, получивший название наведен- ной или техногенной сейсмичности. Суть этого явления заключается в том, что антропогенные воздействия могут приводить к образованию дополнительного напряжения внутри земной коры и стать спусковым крючком подготовленного природой сейсмического события. Примеры случаев наведенной техногенной сейсмичности приведены в таблице 1.

В последние десятилетия многие страны столкнулись с эффектом «синергетического» усиления неблагоприятных факторов различной природы. В частности, погодные условия или стихийные бедствия приводят к серьезным экономическим потерям, что вызывает крупные социальные расходы. Это приводит к тому, что общество становится более неустойчивым к авариям и катастрофам - срабатывает «эффект домино». Данное условие актуализирует необходимость применения системного подхода к исследованию природных и техногенных факторов безопасности.

Таблиия 1

Примеры мощных землетрясений при заполнении водохранилищ

\begin{tabular}{|l|c|c|c|c|c|}
\hline \multicolumn{1}{|c|}{ Место и страна } & $\begin{array}{c}\text { Высота } \\
\text { дамбы }\end{array}$ & $\begin{array}{c}\text { Объем ВДС, } \\
\text { млн м }\end{array}$ & $\begin{array}{c}\text { Год } \\
\text { наполнения }\end{array}$ & $\begin{array}{c}\text { Дата } \\
\text { землетрясения }\end{array}$ & Магнитуда \\
\hline Гувер (США) & 221 & 38,3 & 1936 & 1939 & 5,0 \\
\hline Фенхуан (Китай) & 105 & 11,5 & 1959 & 1961 & 6,1 \\
\hline Монтейнард (Франция) & 130 & 0,3 & 1962 & 1963 & 4,9 \\
\hline Кариба (Замбия) & 128 & 160 & 1958 & 1963 & 5,8 \\
\hline Контра (Швейцария) & 230 & 0,1 & 1964 & 1965 & 5,0 \\
\hline Койна (Индия) & 103 & 2,8 & 1962 & 1967 & 6,5 \\
\hline Бенморе (Новая Зеландия) & 110 & 2,1 & 1965 & 1966 & 5,0 \\
\hline Нурек (Таджикистан) & 300 & 10,5 & 1972 & 1972 & 4,5 \\
\hline
\end{tabular}

Примечание. Разработано авторами по: [Акимов, 2001]. 
Системный анализ признан эффективным инструментом изучения проблем безопасности, в частности обеспечения природно-техногенной безопасности. Актуальность совершенствования системного подхода в их решении обусловливается нерешенностью концептуальных, теоретических и методических аспектов анализа и комплексного оценивания природно-техногенной опасности сложных систем. При этом возникает противоречие между необходимостью проведения анализа состояния различных систем с целью предотвращения ситуаций, обусловленных взаимодействием природных и техногенных факторов, повышения безопасности существующих и вновь создаваемых предприятий, с одной стороны, и отсутствием адекватного научно-методического обеспечения - с другой.

\section{Анализ последних исследований и публикаций}

Проблемам природно-техногенной безопасности уделяется значительное внимание в научных исследованиях как в России, так и за рубежом. Отечественные и зарубежные ученые разработали теоретико-методологические основы качественного и количественного оценивания уровня природно-техногенной безопасности, методы минимизации социально-экономических потерь при реализации опасных ситуаций. Проблемам анализа и управления рисками природно-антропогенного происхождения посвящены научные работы ведущих отечественных и зарубежных ученых (см., например: [Акимов, 2001; Арефьев, 2003; Белов, 2003; Ковалев, 2016; Махутов, 2008; Могилевский, 1999; Прангишвили, 2000]).

В то же время необходимо отметить, что вопросы обеспечения безопасности социального развития, противодействия реальным угрозам развития, формирование нового мировоззрения на проблемы управления природно-техногенными авариями и катастрофами с учетом комплексного решения проблем безопасности, остаются еще недостаточно исследованными. Системность природно-техногенной безопасности требует изучения комплекса факторов, причин и условий возникновения опасностей и определение с их учетом стратегии дальнейшего развития общества.
Анализ результатов отечественных и зарубежных исследований свидетельствует о необходимости разработки теоретических и методологических принципов, которые обеспечили бы системность анализа факторов природно-техногенной безопасности, построение соответствующих моделей природно-антропогенных процессов, являющихся причиной чрезвычайных ситуаций.

\section{Цель работы}

Цель работы - системный анализ проблем природно-техногенной безопасности, разработка концептуальных методов совершенствования системного подхода и построения адекватных моделей исследования проблем природно-техногенной безопасности. За общесистемными принципами выработаны методологические основы анализа взаимосвязей природных, техногенных и социальных факторов природно-техногенной безопасности, обоснованы особенности применения системного подхода к изучению безопасности природно-антропогенных систем.

\section{Методология / методы}

При проведении исследования в качестве методов используются диалектический и статистический анализы, креативный подход, критический историко-экономический обзор, логическая алгоритмизация, рациональное (дискурсивное) суждение.

\section{Результаты и обсуждение}

Проблема безопасности любой системы, прежде всего человеческой, теряет смысл в случае игнорирования антропогенного фактора. В то же время в ее решении ключевую роль играют профессионализм, морально-этические основы, ценности тех людей, которые сталкиваются с опасными объектами: от руководителей до сотрудников, которые находятся на самом объекте. По мировой статистике $80 \%$ всех чрезвычайных ситуаций (ЧС) в воздухе и $70 \%$ на море связаны с человеческим фактором. Поэтому определяющим принципом должно стать то, что человек является одновременно главным объектом и субъек- 


\section{ЭкоЛОГИя}

том исследования проблем природно-техногенной безопасности.

К основным видам опасностей природно-антропогенного характера относятся:

- природного характера: наводнения, цунами, землетрясения, ураганы, сели, тайфуны и т. п.;

- техногенного характера: аварии, катастрофы, пожары, взрывы и т. п.;

- социального характера: социально-психологические опасности, связанные с социальной напряженностью, конфликтностью и т. п.

Для моделирования опасных процессов преимущественно использовалась системная модель «человек - машина». При этом считалось, что факторы опасности сосредоточены в элементе «машина» и высвобождаются преимущественно из-за нарушения связей с элементом «человек». В таких моделях не всегда уделяют должное внимание естественной компоненте опасности, представляющей серьезную угрозу для человека.

Особенности применения системной методологии относительно проблем природно-техногенной безопасности функционирования природно-антропогенных систем заключаются в следующем:

- безопасность - свойство системы обеспечивать нормальный режим ее функционирования с минимальным риском причинения вреда;

- опасность является неизбежным атрибутом функционирования любой системы и рассматривается как возможность перехода системы в состояние, при котором возможны негативные структурно-функциональные изменения, которые могут привести к ее разрушению;

- все реально существующие природноантропогенные опасности можно сгруппировать в три класса: природные, техногенные и социальные, при этом каждый из них обусловлен неадекватными потоками энергии, вещества или информации.

В отличие от других известных методов исследования в системном анализе безопасности важнейшее место принадлежит теоретическому изучению путем формализации и моделирования опасных процессов (см.: [Белов, 2003; Могилевский, 1999; Садовский, 1980; Старик, 2005]).

Современный человек живет в мире природы, техники и социума. Поэтому для исследования проблем природно-техногенной безо- пасности мы предлагаем модель эколого-техногенной системы, которая адекватно отражает основные процессы, определяющие проблемы природно-техногенной безопасности.

В общем под эколого-техногенной системой мы будем понимать определенным образом организованные социум, объекты экономики и техносферы, а также природно-территориальные экосистемы, которые образуют единое структурно-функциональное целое. В рамках эколого-техногенной системы взаимодействуют природные, технологические, социальные процессы, объективные и субъективные факторы. Такие системы относятся к сложным системам с иерархической структурой, обладающие способностью адаптироваться к изменению среды функционирования. Целесообразность выбора эколого-техногенной системы как объекта исследования проблем безопасности природно-антропогенных систем, по нашему мнению, обусловлена следующими факторами:

a) система содержит как источник опасности, так и потенциальную жертву (то есть объект и субъект опасности: экологическую, техногенную и социальную подсистемы);

б) функционирование эколого-техногенной системы адекватно отражает реальные природные, социальные и экономические процессы;

в) модель эколого-техногенной системы позволяет использовать при анализе опасностей общесистемные принципы, что позволяет в определенной степени прогнозировать возникновение опасных ситуаций.

Важным фактором при моделировании является то, что эколого-техногенная система характеризуется трехуровневой степенью ее организации.

Первый уровень - окружающая природная среда как совокупность природных и природно-антропогенных факторов, которые составляют метаинфраструктуру современного производства.

Второй уровень - социум, население как биологические и социальные факторы, образующие определенную среду, в котором происходят демографические, социальные и социально-экономические явления.

Третий уровень - производственно-технологическая структура как совокупность 
технологических процессов, материальноэнергетических и производственно-технических связей, формирующихся в процессе производства.

Внешней средой будем считать все то, что не входит в нее, но может влиять на процесс функционирования или менять систему.

Учитывая общепринятые определения с учетом цели исследования, охарактеризуем основные подсистемы эколого-техногенной системы.

Социальная подсистема (социум) - совокупность группы людей, объединенных определенными отношениями, обусловленными исторически сложившимися способами производства материальных и духовных благ, общей территорией проживания. Во время ее исследования, по нашему мнению, необходимо учитывать положение, которое было известно еще в античные времена - «Мерой всех вещей является человек». Поскольку человек - неотъемлемая часть природы и без нее существование жизни невозможно, то и приоритет во взаимоотношениях между природой и техносферой должен принадлежать первой. Однако в современных условиях в большинстве исследований приоритет в решении научных проблем принадлежит технико-экономическому содержанию, таким понятием, как экономическая эффективность, производительность труда, рентабельность, энергозатратность, которые, несомненно, важны в производстве, но не учитывают природно-биосферного фактора.

Сегодня прогресс техники очевиден, но последствия ее использования приводят биосферу, основные ее составляющие (атмосферу, гидросферу, литосферу) до такого состояния, которое не совместимо с жизнью. Поэтому социальная подсистема занимает особое место в процессах функционирования эколого-техногенной системы.

Экологическая подсистема (окружающая среда) - система абиотических и биотических естественных факторов, непосредственно влияющих на человека, его хозяйственную деятельность в пределах определенной территории. Ее специфика в контексте обеспечения природно-техногенной безопасности заключается в том, что, с одной стороны, она - основа жизнедеятельности как отдельного человека, так и социума в целом, а с другой - источник мощных опасностей, которые представляют угрозу для нормального функционирования общества в целом.

Сегодня техносфера - важнейшая часть материальной технической культуры индустриальной цивилизации. Это не столько механизм трансформации природы в потребительские блага, сколько именно окружающая среда, превращенная антропогенной деятельностью в техноприродный территориальный комплекс: техноландшафты. Техноландшафт пространственно обусловленная среда функционирования сложных социотехнических систем, которые содержат разнообразные социальные и технические подсистемы, в том числе и опасные производственные объекты.

Сложность и разнородность проблемы безопасности обусловливает необходимость применения моделирования и формализации при исследовании соответствующих процессов в рамках эколого-техногенной системы. При этом формализацией называют специально систематизированное адекватное представление в форме некоторых искусственных объектов (моделей), а моделированием - использование полученных объектов, обладающих определенным сходством с оригиналом, для получения новых знаний об исследуемых процессах.

Одной из важных целей моделирования проблем опасности является прогнозирование. С точки зрения формализации и использования математических методов оценки и прогнозирования опасностей последние характеризуются как определение вероятности возникновения неблагоприятных событий (кризисных явлений и катастрофических ситуаций) и возможных убытков от них, обнаруживающих необходимый уровень защищенности жизненно важных интересов личности, общества и государства.

С позиций общей теории систем мы выделяем три вида процессов в контексте возможности прогнозирования безопасности их функционирования (см. табл. 2).

Так, наименее прогнозируемыми являются стохастические системы, в которых процессы полностью непредсказуемы, мало прогнозируемыми - системы, характеризующиеся динамическим хаосом, а наиболее прогнозируемыми - системы, описываемые теорией динамических непрерывных систем. 
Формализация процессов природно-техногенных опасностей

\begin{tabular}{|c|c|c|c|}
\hline $\begin{array}{c}\text { Характер функциони- } \\
\text { рования систем }\end{array}$ & $\begin{array}{c}\text { Теории и модели } \\
\text { исследования }\end{array}$ & $\begin{array}{c}\text { Возможности } \\
\text { прогнозирования }\end{array}$ & Горизонт прогноза \\
\hline Динамические & $\begin{array}{l}\text { Теория динамических } \\
\text { непрерывных систем }\end{array}$ & $\begin{array}{l}\text { Поддается прогнозиро- } \\
\text { ванию. } \\
\text { Будущее однозначно } \\
\text { определяется прошлым } \\
\text { и является полностью } \\
\text { предсказуемым }\end{array}$ & Неограниченный \\
\hline Стохастические & $\begin{array}{l}\text { Теория вероятности и } \\
\text { математическая стати- } \\
\text { стика, вероятно-статис- } \\
\text { тические модели }\end{array}$ & $\begin{array}{l}\text { Будущее не зависит от } \\
\text { прошлого. } \\
\text { Процессы полностью } \\
\text { непредсказуемы }\end{array}$ & Недостающий \\
\hline Динамический хаос & $\begin{array}{l}\text { Теория сложности и са- } \\
\text { моорганизованной кри- } \\
\text { тичности модели иерар- } \\
\text { хических систем и не- } \\
\text { линейной динамики }\end{array}$ & $\begin{array}{l}\text { Будущее может быть } \\
\text { предсказуемо на не- } \\
\text { большой промежуток } \\
\text { времени }\end{array}$ & Ограниченный \\
\hline
\end{tabular}

Примечание. Разработано авторами по: [Могилевский, 1999; Старик, 2005].

Проблемы природно-техногенной безопасности во многом связаны с характером функционирования техносферы. Причина высокого процентного показателя техногенных аварий и катастроф заключается в нарушении пропорций в системе «человек - машина». Любая система, в том числе и рассматриваемая, функционирует эффективно, если главные ее элементы соответствуют друг другу. Увеличение темпов научно-технического прогресса заключается в росте энергоемкости техники и технологических процессов, многократном увеличении информационных потоков, тогда как человек остается практически неизменным: острота зрения, время реакции, оперативная память и другие психофизиологические критерии, сформированные в процессе эволюции, остаются неизменными.

Современная техногенная сфера накопила в себе огромные потенциальные опасности, которые могут катастрофически реализовываться при возникновении ЧС на объектах. Несмотря на то, что они более прогнозируемые, с учетом процесса старения основного оборудования и снижения профессионального уровня персонала в ближайшие годы следует ожидать увеличения частоты и масштабов последствий от аварий и катастроф на потенциально опасных техногенных объектах.

Для экосистем и социума существуют определенные общие алгоритмы, закономер- ности и единые ценности, согласно которым происходит их функционирование. Это общее для биоты и человечества заключается в следующем:

- существование единой материальной и энергоинформационной основы локализованных в пределах пространства и времени, в формах материальных объектов;

- системность структуры, функций и иерархичность;

- многопараметричность, многофакторность, стохастичность;

- стремление к поддержанию оптимизированного и эффективного существования, жизнеспособности;

- сохранение определенной упорядоченности, структуры на протяжении значительных, но характерных для жизненного цикла систем, периодов времени;

- системность жизнедеятельности, допускающая динамику, вариативность, мутации, трансформации, наличие новаций и самоактивности (инициатив) целого и частей;

- самовоспроизводства в целом и частях и т. п.;

- адаптивность по отношению к условиям за счет лабильности и самоорганизации, реорганизации и саморазвития;

- наличие фаз перехода («переходных состояний») и «снятия» предыдущих форм, качеств и состояний в ходе развития к высшему или низшему. 
Используя методологию системного анализа, мы выделили важнейшие методологические принципы, которых необходимо придерживаться, исследуя эколого-техногенные системы.

1. Принцип оптимальной простоты. Решение социальных, экологических и технологических проблем должно быть согласовано с главной целью функционирования экологотехногенной системы, которое определяется социумом, основываться на точных данных относительно структуры и характера функционирования эколого-техногенной системы.

2. Принцип социальной ответственности.

3. Принцип междисциплинарности. Эколого-техногенная система является разнородной, поэтому необходимо использовать междисциплинарные подходы.

4. Принцип объективности. Каждая подсистема эколого-техногенной системы функционирует в соответствии с объективными закономерностями.

5. Принцип иерархии целей, ценностей и «экономического реализма».

6. Принцип анализа постоянно развивающихся систем. Во время изучения многих явлений, прежде всего в социальной и техногенной подсистемах, свойства системы могут значительно изменяться, что должно стать предметом особого внимания ученых.

7. Принцип системного синтеза. В рассмотрении функционирования эколого-техногенной системы и любой ее подсистемы необходимо выявлять главные параметры структуры и процессы, обусловливающие динамику в интервалах времени, задаваемых целью исследования.

Согласно предложенной модели экологотехногенной системы дадим определение природно-техногенной опасности: это свойство эколого-техногенной системы, характеризующее состояние системы, что обусловливает возможность нарушения нормального функционирования последней и появление убытков в пределах каждой подсистемы. Природно-техногенную безопасность эколого-техногенной системы будем рассматривать как состояние сложной системы, обеспечивающее нормальное функционирование системы в целом, отдельных ее подсистем и достижение поставленных целей функционирования.
Природно-техногенная безопасность тесно связана ЧС. Под ЧС эколого-техногенной системы мы будем понимать существенное изменение структуры или характера функционирования системы, что вызывает появление убытков, обусловленных, как правило, разрушительным влиянием потоков энергии, вещества или информации. К основным видам ЧС в рамках эколого-техногенной системы относятся: техногенные катастрофы, природные стихийные бедствия, социальные катаклизмы. Убыток эколого-техногенной системы будем трактовать как меру или результат изменения характера функционирования или структуры подсистем эколого-техногенной системы, характеризующееся нарушением целостности или ухудшения других системных факторов, что затрудняет или делает невозможным выполнение основного назначения системы или отдельных ее подсистем.

Предложенная модель позволяет классифицировать риски функционирования сложных систем.

Вариант классификации рисков функционирования эколого-техногенной системы в соответствии с ее структурой приведен в таблице 3.

На основе общепризнанных подходов к системному анализу сложных систем можно сформулировать основные этапы системного анализа проблем природно-техногенной безопасности:

I. Выявление проблемы безопасности исследуемого объекта.

II. Определение эколого-техногенной системы.

III. Анализ структуры и характера функционирования системы.

IV. Определение общих целей и критериев нормального функционирования системы.

V. Декомпозиция целей функционирования системы.

VI. Прогноз и анализ будущих условий.

VII. Оценка целей и средств достижения цели исследования.

VIII. Выбор вариантов.

IX. Анализ функционирования системы с позиций обеспечения безопасности.

$\mathrm{X}$. Разработка интегральных показателей безопасного функционирования системы.

XI. Проектирование механизмов управления безопасностью эколого-техногенной системы. 
Классификация опасностей и рисков эколого-техногенной системы

\begin{tabular}{|l|c|c|c|}
\hline \multirow{2}{*}{ Источник опасности } & \multicolumn{3}{|c|}{ Субъекты риска опасности (подсистема ЭТС) / риски (подсистема ЭТС) } \\
\cline { 2 - 4 } & Окружающая среда & Социум & Техносфера \\
\hline Окружающая среда & Экологичный & Природно-социальный & Природно-техногенный \\
\hline Социум & Социоприродный & Социальный & Социотехногенный \\
\hline Техносфера & Техноприродный & Техносоциальный & Техногенный \\
\hline
\end{tabular}

Примечание. Разработано авторами по: [Акимов, 2001; Арефьев, 2003].

\section{Выводы}

Системный подход к обеспечению природно-техногенной безопасности должен основываться на общих исходных понятиях и предпосылках:

a) опасности необходимо рассматривать как обязательный атрибут функционирования любой сложной системы;

б) объектом системного анализа природно-техногенной безопасности должна стать эколого-техногенная система, основными подсистемами которой являются экологическая, социальная и техногенная;

в) природно-техногенную опасность можно интерпретировать как возможность нарушения нормального характера функционирования эколого-техногенной системы;

г) системный подход к анализу проблем природно-техногенной безопасности должен основываться на общесистемных принципах функционирования сложных систем;

д) важным результатом анализа эколого-техногенных систем должен стать прогноз характера функционирования системы с целью уменьшения убытков при реализации опасных ситуаций.

Целесообразность выбора эколого-техногенной системы как объекта системного анализа природно-техногенной безопасности аргументируется следующими факторами:

a) система содержит источник опасности и потенциальную жертву;

б) функционирование эколого-техногенной системы охватывает носителей всех типов опасностей и предпосылки возникновения неблагоприятных ситуаций функционирования сложных систем.

Длительное время господствовала концепция «абсолютной безопасности»-считалось, что можно создать абсолютно безопасную систему любой сложности. Сегодня стало очевидным, что такое маловероятно: абсолютной является лишь «опасность». Для принятия эффективных управленческих решений необходима количественная информация об уровне опасностей и угроз, их зависимости от различных факторов. Для ееполучения нужен специальный инструментарий (методы, модели, алгоритмы), который дает возможность сформировать соответствующую систему поддержки принятия решений в области прогнозирования и минимизации последствий ЧС природного и техногенного характера.

Несмотря на то, что в научной литературе ранее рассматривалась проблема безопасности, сегодня практически нет исследований, посвященных специфике использования системного подхода при формировании механизмов управления природно-техногенной безопасностью. Поэтому актуальным является вопрос о разработке на основе системного подхода теоретических основ управления природно-техногенной безопасностью. Особого внимания требует подготовка основ риск-ориентированного анализа последствий ЧС и определение интегральных критериев оценки уровня природно-техногенной безопасности, совершенствование механизма государственного регулирования и форм управления в этой сфере.

\section{СПИСОК ЛИТЕРАТУРЫ}

Акимов, В. А. Методический аппарат исследования природного и техногенного риска / В. А. Акимов // Безопасность жизнедеятельности. 2001. - № 2. - C. 34-38.

Арефьев, С. С. Эпицентральные сейсмологические исследования / С. С. Арефьев. - М. : Академкнига, 2003. -375 с

Белов, П. Г. Системный анализ и моделирование опасных процессов в техносфере / П. Г. Белов. - М. : Академия, 2003. - 507 c.

Ковалев, Б. И. Экологическая безопасность / Б. И. Ковалев, Р. Б. Ковалев. -Брянск : БГАУ, 2016. -232 с. 
Махутов, Н. А. Прочность и безопасность: фундаментальные и прикладные исследования / Н. А. Махутов. - Новосибирск : Наука, 2008. $-528 \mathrm{c}$.

Могилевский, В. Д. Методология систем: вербальный подход / В. Д. Могилевский. - М. : Экономика, 1999.-251 с.

Прангишвили, И. В. Системный подход и общесистемные закономерности / И. В. Прангишвили. - М. : Синтег, 2000. -528 с.

Садовский, В. Н. Системный подход и общая теория систем статус, основные проблемы и перспективы развития / В. Н. Садовский // Системные исследования: ежегодник. 1979. - М. : Наука, 1980. - С. 29-54.

Старик, О. Г. Системотология : учебник/ О. Г. Старик. Киев : Центр учебной литературы, 2005. -231 с.

\section{REFERENCES}

Akimov V.A. Metodicheskiy apparat issledovaniya prirodnogo i tekhnogennogo riska. Bezopasnost zhiznedeyatelnosti, 2001, no. 2, pp. 34-38.
Arefev S.S. Epitsentralnye seysmologicheskie issledovaniya. Moscow, Akademkniga Publ., 2003. $375 \mathrm{p}$

Belov P.G. Sistemnyy analiz $i$ modelirovanie opasnykh protsessov $v$ tekhnosfere. Moscow, Akademiya Publ., 2003. 507 p.

Kovalev, B.I. Ekologicheskaya bezopasnost. Bryansk, BGAU Publ., 2016. 232 p.

Makhutov N.A. Prochnost $i$ bezopasnost: fundamentalnye i prikladnye issledovaniya. Novosibirsk, Nauka Publ., 2008. 528 p.

Mogilevskiy V.D. Metodologiya sistem: verbalnyy podkhod. Moscow, Ekonomika Publ., 1999. $251 \mathrm{p}$.

Prangishvili I.V. Sistemnyy podkhod i obshchesistemnye zakonomernosti. Moscow, Sinteg Publ., 2000. $528 \mathrm{p}$.

Sadovskiy V.N. Sistemnyy podkhod i obshchaya teoriya sistem status, osnovnye problemy i perspektivy razvitiya. Sistemnye issledovaniya: ehegodnik. 1979. Moscow, Nauka Publ., 1980, pp. 29-54.

Starik O.G. Sistemotologiya : uchebnik. Kiev, Centr uchebnoy literatury Publ., 2005. 231 p.

\section{Information about the Authors}

Yakub E. Dadaev, Senior Lecturer, Department of Commerce and Marketing, Chechen State University, A. Sheripova St., 32, 364024 Grozny, Russian Federation, dadaev.ya.82@mail.ru, https://orcid.org/0000-0002-8439-3360

Samart D. Hazhmuradova, Student, Chechen State University, A. Sheripova St., 32, 364024 Grozny, Russian Federation, khazhmuradova.samart@mail.ru, https://orcid.org/0000-0002-0391-6431

\section{Информация об авторах}

Якуб Элхазурович Дадаев, старший преподаватель кафедры коммерции и маркетинга, Чеченский государственный университет, ул. А. Шерипова, 32, 364024 г. Грозный, Российская Федерация, dadaev.ya.82@mail.ru, https://orcid.org/0000-0002-8439-3360

Самарт Динисламовна Хажмурадова, студент, Чеченский государственный университет, ул. А. Шерипова, 32, 364024 г. Грозный, Российская Федерация, khazhmuradova.samart@mail.ru, https://orcid.org/0000-0002-0391-6431 